\title{
Procedures and criteria for evaluating academic legal publications: Results of a survey in Switzerland
}

\author{
Martin Schmied $^{1 *}$, Karin Byland ${ }^{2}$ and Andreas Lienhard ${ }^{2}$ \\ ${ }^{1}$ Center of Competence for Public Management, University of Bern, 3001 Bern, Switzerland and ${ }^{2}$ Faculty of Law, \\ University of Bern, 3001 Bern, Switzerland \\ *Corresponding author. Email: martin.schmied@kpm.unibe.ch
}

\begin{abstract}
As in other European countries, there has been a growing pressure on assessing academic research in Switzerland. This also applies to the field of academic legal research. This article, which is based on a survey in Switzerland, aims to explore the assessment procedures and criteria that are used to evaluate academic legal publications and to judge their suitability. In doing so, two important principles have to be respected: first, the suitability of assessment procedures and quality criteria depends on the context and the purpose of the assessment. Additionally, peculiarities of research (and publication) behaviour in academic legal research have to be taken into account. Second, researchers of a certain field need to be involved into the process of defining how to evaluate research (bottom-up approach).

On the basis of literature analysis, the actual use and suitability of assessment procedures and criteria were explored in a survey among editors of law journals, law professors, and practitioners (lawyers). Results show that academic legal publications in Switzerland are mainly being assessed by means of (simple) peer review, whereby double-blind peer review procedures are rarely used. There appears to be some common ground among stakeholders concerning appropriate criteria, but the substance of criteria remains unclear. Bibliometric methods and indicators are rarely being used and generally do not yield meaningful results.
\end{abstract}

Key words: research evaluation; academic legal research; evaluation procedures; quality criteria.

\section{Introduction}

One of the key characteristics and core tasks of universities is that they conduct high-quality research. ${ }^{1}$ In Switzerland, the Higher Education Act (HEdA), which came into force on 1 January 2015, stipulates that universities have to adopt a quality assurance system that also includes a process for evaluating research. To ensure that suitable assessment procedures are applied, researchers are required to come up with appropriate evaluation procedures and criteria. At the same time, researchers themselves need tools to be able to assess research work. It should be noted that the evaluation of research work has been important for a long time, for example, when assessing dissertations or deciding who is to be awarded prizes.

However, there is widespread criticism concerning research evaluation and quality assurance in general. Specifically, a disproportionate administrative expenditure (Amschwand 2014: 225f; Costa 2015: 409ff), limits on academic freedom (Van Gestel 2015: 32; Chérot 2015: 251f; Maier 2015: 444), and unwelcome incentives (Bégasse de Dhaem and Van Waeyenberge 2015: 255ff; Chérot 2015: 239ff), as well as general reservations about the meaningfulness of applied assessment procedures are cited. ${ }^{2}$ Processes for assessing research publications are controversial (Van Gestel and Vranken 2011: 914). Criticism is primarily directed towards the way in which the evaluation is carried out (see e.g. Pichonnaz 2014: 379f; Zuppiroli 2015: 17ff; Chérot 2015: 239ff; Aseeva 2015: 277ff).

These developments in relation to research evaluation also affect academic legal research. The question arises of whether researchers, research institutions, or legal editors have adequate procedures and quality criteria for evaluating research. In particular, procedures should take sufficient 
and appropriate account of the peculiarities of legal studies and the special characteristics of the various evaluation situations.

Studying the evaluation of academic legal research in Europe is a recent phenomenon. Since the 1980s and increasingly since the 1990s, there has been a transnational evaluation debate, and procedures for evaluating legal research units are being explored and devised. ${ }^{3}$ In other (European) countries, several studies have tackled the issue of evaluating academic legal research. ${ }^{4}$ The subject of research in these studies is usually evaluating research produced by entire units and/or by individual researchers. Generally, these reports include no information that would permit any conclusions to be drawn as to the success of the procedure developed. ${ }^{5}$ In most cases the research evaluation has had the aim of distinguishing the "best" research work from the others (benchmarking). The work assessed shows that there is no clear consensus as to quality criteria in the research community (see Lienhard et al. 2016: 220). Several projects carried out have even met with considerable resistance and criticism on the part of the research community and/or have not been completed (see Gutwirth 2009: 74). Therefore, it can be said that legal scholarship lacks an intensive debate on the criteria and indicators that evidence the quality of legal research.

The assessment of research projects is not a self-contained operation, but it depends on the assessment context. ${ }^{6}$ The concept of quality is linked to the context and purpose of the evaluation (Reichert 2013: 29). The expectations with regard to the product of research will differ depending on the discipline, publication medium (for example, articles or monographs), or the expectations of those involved. Evaluation is ultimately determined by the goals and effects of the research in questions and the extent to which these requirements are fulfilled and implemented. This article only considers situations in which academic legal publications are evaluated. This is because publications provide us with the key results of academic legal research. While the debate about the quality of legal research is generally broad and involves the assessment of further subjects (for example, the performance of researchers and research institutions), the quality of publications, as the main product of research, always plays a central role.

Specifically, this includes the evaluation of scientific articles carried out by editors of journals with a view to deciding whether to accept the work for publication, as well as the assessment of publications by professors. The aim is to get an overview of the practice of assessing academic legal publications as well as to explore suitable procedures and criteria to evaluate academic legal publications.

Therefore this article focuses on the following questions:

- What procedures and criteria ${ }^{7}$ exist for assessing the quality of academic legal publications?

- What procedures and criteria are suitable for assessing the quality of academic legal publications?

This article was created in the course of a research project of the universities of Bern and Geneva which has been conducted as part of an overarching research project coordinated by the Rectors' Conference of the Swiss Universities (CRUS, Project 2008-2011, CRUS, SUK-Programm 2013-2016) and initiated by the Swiss University Conference (SUK). ${ }^{8}$ The aim of the overarching program was to provide Swiss universities with appropriate instruments for evaluating research work with a special focus on making the research products visible. The key results concerning the evaluation of academic legal research have been published in a book (Lienhard et al. 2016). This contribution considers selected aspects of the results already published in this book.

\section{Setting the scene: academic legal research, evaluation methods, and criteria}

\subsection{Peculiarities of academic legal research \\ 2.1.1 General remarks}

The subject of the investigation is the quality of academic legal research. The following remarks provide a brief explanation of this term: on the one hand, only scientific research is considered. The definition of what is scientific is the subject of a continuous communicative process for researchers (see Herbert and Kaube 2008: 51). In continental European legal science, there is a debate from time to time as to whether the traditional dogmatic legal research can in fact be regarded as scientific at all (Larenz and Canaris 1995: 19ff). ${ }^{9}$ For the purposes of this contribution, a broader definition of what research counts as scientific has been chosen. Research may be regarded as scientific firstly if it is conducted independently and secondly if it demonstrates a certain degree of abstraction (see Lienhard et al. 2016: 23ff). This distinguishes scientific research from the legal practice in particular; however, it covers both "traditional" dogmatic research into the content of the law and its application as well as research that uses empirical or other methods (see Larenz and Canaris 1995: 11ff). In short, we define academic legal research as research on the subject of law, regardless of the method, academic discipline, or author (professor, lawyer, etc.) as long as it is of scientific character (i.e. the research is conducted independently and demonstrates a certain degree of abstraction).

On the other hand, ascertaining the quality of academic legal research is fundamental for developing quality criteria. Here, "quality" is defined as the degree to which research is considered "good" by various stakeholders. The definition of what is "good" is up to these stakeholders. In the humanities, to which some types of legal research have close similarities, there is still no generally recognized definition of what is good research or good scientific quality (Lack and Markschies 2008: 1ff). However, this does not mean that there is no concept of quality. Quality assessments are also partly based on the assessors' subjective and unexpressed notions of quality (their tacit knowledge skills; Herbert and Kaube 2008: 40). The practical value of academic legal research is not regarded as an element of quality in this article. ${ }^{10}$

Different countries have distinct legal systems and legal traditions. There are attempts to typify legal systems and to assign national legal systems to these types (see Glenn 2014). The specific legal system also affects the way research in the field of law is conducted and its scope. However, sound analysis and comparison of the practice of publishing and of how academic legal publications are evaluated throughout Europe are currently missing.

The following outline of peculiarities of academic legal research is based on the practice of law in Switzerland. The legal system of Switzerland is often classed as a civil law system with close similarities to other Germanic legal systems (see Kunz 2006: 50). In general, this means that the following peculiarities do not hold true for all legal systems, but similar features might (and will) be present in academic legal research in many legal systems.

\subsubsection{Segmentation}

As mentioned, the production of academic legal research depends on the national culture and legal systems (see also Lienhard, 
Amschwand and Herrmann 2013: 421ff). In Switzerland, for example, academic legal research is influenced by the legislation at the various federalist levels (communal, cantonal, federal, and international levels). It is also subdivided into various, more or less widespread, specialist areas such as private, criminal, and public or international law (Lienhard and Amschwand 2010: 11). The consequence of this segmentation is an abundance of different research (in the sense of research topics, questions, and areas of application) and a large number of types of publication (monographs, articles, text books, commentaries, case notes, etc.), normally with low circulation figures but little in the way of competition.

\subsubsection{Language}

In addition to the cultural and organizational structure of a country, the national languages are also a decisive factor in determining how academic legal research is carried out. In contrast to research in economics or natural sciences, academic legal research that focuses on the national context is rarely published in English, instead it is being published in a national language-normally the mother tongue of the authors. In Switzerland, for example, German, French, Italian, and Romansh are the four national languages. Publications aimed at an international readership are however normally written in English and, in the case of renowned authors, published abroad (Pichonnaz 2014: 394). One interesting question is whether and how language relates to the quality of a legal publication. It can be debated whether articles that are written for a broad audience, published in English-language journals with a high frequency of appearance, are necessarily better than articles written in either French or German for a specialized journal that has fewer readers and appears less often (Lienhard et al. 2016: 37).

\subsubsection{Publication behaviour and types of publication}

The specific publication behaviour and the customary types of publications (articles, monographs, text books, commentaries, case notes, etc.) for academic legal research matters too. Again, the choice of the publication type depends on the legal system and the legal culture. The standing of individual types of publications varies from country to country (Pichonnaz 2014: 382). In Switzerland, academic legal researchers publish a considerable proportion of their research results as books. Most publications by individuals (Gutwirth 2009: 73) tend to appear in the form of monographs, judgement reviews, and commentaries rather than in "rated journals" (Grapatin et al. 2012: 42). Festschrifts, anthologies, and symposium papers are also part of academic legal output. Monographs are commonly revised and then published again (new editions) (Lienhard and Amschwand 2010: 11). Additionally, research publications appear in not only relevant law journals but also journals of professional and specialist associations as well as in non-legal scientific journals. 'Core journals', typical of the natural sciences, are less prevalent in legal science. In effect, journals are less important than monographs. Finally, a significant amount of academic legal research is also carried out in order to produce legal opinions (Lienhard and Amschwand 2010: 11).

\subsubsection{Rankings}

While law journals may have a good or bad reputation among legal scholars and practitioners for the quality of their content, there is no generally recognized ranking of law journals or legal publishers in Switzerland and Europe. This is not surprising: because legal scholars often publish in their national language, there is no lingua franca in legal research. The majority of the European law journals are therefore not published in English. This hinders the accessibility for foreign scholars and therefore limits their impact.

A common European law journal ranking would imply to compare journals written in different languages for different audiences (general interest versus specialized or theoretical journals) with different quality assessment methods (peer-reviewed versus editorial reviewed or student edited) by authors from different backgrounds (academics versus professionals) and legal cultures (common law versus civil law countries) (Van Gestel 2015: 184). Besides, a survey among legal scholars in Switzerland has shown that they are looking very critically at measuring research quality via rankings, citation counting, and other quantitative evaluation methods (Lienhard et al. 2016: 185, 232). The same seems to be true at the European level (Stolker 2014: 245).

\subsubsection{Citations}

One feature of legal publication behaviour in Switzerland is the way in which citations are used: in academic legal publications, court judgements are often cited, while reference is made in court judgements to academic legal literature (Lienhard and Amschwand 2010: 12). The referencing and citing in academic legal research indicate that case law is included in addition to legal literature. Citations are made-more than in other specialist areas-with a critical eye to the literature and/or the court judgement.

\subsubsection{Self-contained databases}

There is no uniform or complete national bibliographical database for academic legal articles that could serve as the basis for bibliometric analyses. Swiss specialist bibliographies, library catalogues, and the various research databases at the universities, which are not linked to each other, provide an incomplete picture of the production of knowledge. This is in part due to the number of publications analysed, to language bias, to a lack of attention paid in some cases to monographs and anthologies, to fragmentation in communication in the various specialized areas, to the unclear status of popular scientific and grey literature, and to the small number of statistically analysable and comparable entries (Hornbostel 2008: 60). As a result, contributions to Swiss legal research rarely find their way into Thomson Reuters' 'Web of Science' or comparable international databases.

\subsubsection{Academic legal research methods}

Academic legal research makes use of specific methods. In Switzerland and other continental European countries, academic legal research is widely regarded as similar to the humanities, because academic legal working methods consist largely of a process of comprehension, the method of legal hermeneutics (Tschentscher 2003: 59f). The aim is to structure the law, to identify (in)consistencies, and to enrich the existing law through research work (De Jong et al. 2011: 10). This constant scientific debate on the subject leads to the creation of dogmatic legal theories that combine the various assessments of interests (Arzt 1996: 89). Results in academic legal research are deduced by logical argument that is based on a qualitative approach. Academic legal research results are repeatedly challenged in the course of further research work. In contrast to the natural sciences and in common with the humanities and social sciences, the aim is not to achieve a "final" research result. Knowledge 
does not become obsolete (CEST 2007: 19), but is expanded continuously through the scientific discourse. However, empirical research, which looks at the way the law is applied, and the effects of the law on society, as well as legal history, legal philosophy, and other disciplines, are also part of legal science in its broader sense.

\subsubsection{Link with society and the legal practice}

Legal research at universities is not conducted in a room sealed off from society, politics, and professional practice; on the contrary, it has strong links with these. An ongoing detailed exchange takes place with various non-university actors (Shapiro 1992: 337). For example, judges and practising lawyers make extensive use of academic legal literature (Lienhard and Amschwand 2010: 11). Case law regularly refers to areas of academic legal research of practical relevance that focus on social developments outside the university setting. Whether a practitioner is a knowledge producer or a consumer can be hard to determine in individual cases. Commonly one and the same person may be active in both legal research and legal practice. Many legal academics have jobs at universities and in the private or public sector, for example, in the courts or at legal advice centres (De Jong et al. 2011: 10; Gutwirth 2009: 70). At the same time, judges and practising lawyers also publish papers or scientific articles in journals or teach law at a university. This makes it difficult to classify publications into the categories of research or practice. In legal science, there is no clear line between popular scientific publications, grey literature, and research literature aimed at the academic community.

In some countries (particularly the USA), there is a debate over a perceived growing disjunction between legal practice and legal scholarship (see Edwards 1992: 34ff; Posner 1992: 1921ff). In the USA, a considerable amount of literature in the field of law comprises theoretical papers that have little to no relevance for legal practice (Edwards 1992: 46f). One of the reasons for that is seen in the important position of interdisciplinary approaches (such as law and economics or critical legal studies). In contrast, in many continental European countries, academic legal publications (still) predominantly deal with practical legal questions and have a significant impact on jurisprudence by courts and on law practice (see Kischel 2015: 470ff).

\subsection{Determining evaluation methods and criteria}

Various procedures are used to assess publications. In general, a distinction is made here between peer review and bibliometrics. The peer review is the oldest procedure in scientific evaluation (Kronick 1990: 1321f). It is a quality assurance process in which scientific works are commented on and evaluated, i.e. reviewed by persons of equal professional standing (peers). Peers include scholars working in the same specialist field [pure peer review (Kozar 1999: 44)] and scholars from another discipline [extended peer review (Kozar 1999: 44)]. A distinction can be made between simple peer review procedures and the single-blind peer review or indeed the double-blind peer review.

In contrast to peer review procedures, bibliometrics makes only indirect comments on the quality of scientific publications, for example, by numerically assessing articles that have been published in the course of peer review procedures. Bibliometrics is defined as the application of mathematical and statistical methods to bibliographical information (Havemann 2009: 7), such as articles in scientific journals, dissertations, grey literature, and reports
(Gingras 2014: 15). It is however based on a categorization that is qualitative in its origins.

Evaluation criteria are characteristics in respect of which the subject of an investigation can be assigned a value. A criterion can be described using aspects and operationalized using indicators. ${ }^{11}$ Most quality indicators thus measure not quality itself (Donovan 2008: 77) but factors indicative of it (proxy variables).

The decision on appropriate procedures, criteria, and indicators for assessing the quality of (academic legal) research can be made by various different stakeholders with a view towards achieving various different goals. Here, a bottom-up approach is used. This means that the evaluation procedures and criteria should first be determined by the researchers themselves. This course of action can be justified on the following two grounds:

On the one hand, according to the Swiss Federal Constitution, the principles of scientific freedom and university autonomy have to be respected. As a consequence, the fundamentals and content of quality assurance and in particular of evaluations have to be decided by the researchers and the universities themselves. Accordingly, in the national accreditation process, universities must simply show that a quality assurance procedure exists (Art. 30a para. 1 HEdA); the method, the regularity, the criteria, or the scope of the research evaluation is not specified. Quality assurance itself is therefore the responsibility of the universities (Lienhard et al. 2015: 74).

On the other hand, members of the research community also take the view that researchers ought to decide how the assessment of research projects is organized, or that they should at least be adequately involved in the process (Hug, Ochsner and Daniel 2014: 58; Seckelmann 2012: 225). ${ }^{12}$ The researchers should be consulted when devising the relevant methods and instruments. Analysing the content of high-quality research and adopting quality criteria for evaluating it are an indispensable part of this process. It is therefore the duty of the academic community to decide on and continually update these criteria. ${ }^{13}$ This approach offers the advantage on the one hand that each discipline can adopt its own adequate quality criteria and on the other hand that the level of acceptance of the applied quality criteria within the research community increases (Hug, Ochsner and Daniel 2010: 91). Hug et al. propose that when devising and applying criteria, the concept of quality within the research community should be used and an attempt should be made to achieve a consensus on suitable quality criteria within the research community (Hug, Ochsner and Daniel 2014: 58f).

As far as we are aware, the legal research community has so far not been asked in a systematic manner how they assess the quality of academic legal research and how it could be adequately measured or evaluated. As mentioned (Section 2.1.9), academic legal publications are not only being produced and evaluated by legal scholars. A considerable part also involves lawyers or editors of law journals. They also form part of the research community that determines the quality of academic legal research and has to define appropriate methods and criteria/indicators to assess academic legal research. Their preferences therefore have to be taken into account too.

\section{Methods}

To determine the application and suitability of evaluation procedures and criteria/indicators, a survey with the aforementioned stakeholders was conducted. The survey covered a variety of evaluation objects and situations (including e.g. evaluations of research 
units or of researchers) and included questions about the importance of several criteria for assessing academic legal publications. ${ }^{14}$

To establish existing methods and criteria, in a first step, the potential procedures and criteria used to evaluate academic legal publications were identified by means of an analysis of literature (for an overview, see Lienhard, Amschwand and Herrmann 2013). In a second step, editors of Swiss law journals were questioned. The electronic questionnaire containing semi-open questions was sent to 101 law journals (see Lienhard et al. 2016, Table 25 in Annex 2). An existing list of journals was taken from a previous research project (Lienhard et al. 2016: 22) and slightly expanded. Further, 43 editors completed the questionnaire in full. The response rate was $43 \%$. Respondents who had opted out of the electronic survey during the process of responding to it, were not included in the final sample. Respondents were given the opportunity to comment in special text boxes, which were separated and put in a different database in order to preserve anonymity. Additionally, to identify which criteria are being applied/considered by the relevant university stakeholders, an analysis of legal documents of universities was conducted.

To determine the suitability of evaluation methods and criteria/ indicators, a survey of law professors and practising lawyers (in addition to the editors of Swiss law journals mentioned above) has been conducted. The participants were given a list of evaluation criteria. The criteria were compiled from the literature (in particular Hug, Ochsner and Daniel 2013: 369ff) and supplemented with criteria from legal science. Several pre-tests of these criteria were carried out. A main focus was on the survey of law professors. An electronic questionnaire with 26 questions was sent to all Swiss law professors. Email addresses were provided by the law faculties and the lists were replicated with the addresses on the faculty websites. Only legal scholars with the status of professor employed at law schools were included in the survey (e.g. full professors, assistant professors, associate professors, honorary professors, etc.). In total, 398 law professors were sent the questionnaire, and 137 completed it (response rate, $34 \%) .{ }^{15}$ Again, individual statements were anonymized. For the survey of practising lawyers, a random selection of members of the Swiss Bar Association (Schweizerischer Anwaltsverband, SAV) was questioned. The respondents were contacted between May and June 2014. The survey included $10 \%$ of the practising lawyers appearing on the SAV register who practise in one of the official Swiss languages ${ }^{16} ; 873$ lawyers were invited to participate in the survey, and 231 completed the questionnaire in full (response rate, $26 \%)$.

All surveys were carried out using an online questionnaire. ${ }^{17}$

\section{Results}

\subsection{General remarks}

The description of the outcome of the survey is organized in two parts. Results concerning procedures to assess academic legal publications are presented in Section 4.2, whereas results concerning criteria are presented in Section 4.3. Both chapters are split (according to the leading questions) between a section about existing procedures and criteria and a section about suitable procedures and criteria.

Mention must be made of three reservations about the chosen research methodology that should be borne in mind when interpreting the results: firstly only law professors employed in a law faculty at the time of the survey took part in the survey (besides practising lawyers and editors). Naturally the views of junior legal academics and of law professors in other faculties on research evaluation would also be of interest. Secondly the answers given in a survey are always dependent on the procedure chosen. Because opinions, assessments, and ratings were asked for, the answers may also include elements that are desirable from the point of view of the person questioned or which are regarded as socially acceptable. Thirdly limiting the survey to the chosen evaluation situations automatically means that applying certain evaluation procedures and criteria makes less sense.

\subsection{Evaluation procedures}

\subsubsection{Existing evaluation procedures}

Academic legal publications are regularly evaluated by a variety of actors. The first that come to mind are the editors of law journals. Editors were asked about who decides about the acceptance of publications at their journal:

A good $84 \%$ of the editorial boards decide whether to publish an article on their own, without consulting external experts. Only $13 \%$ of the editors of law journals make any use of external experts when assessing articles submitted (5 out of 38 journals-cf. Fig. 1). External experts are consulted at these journals if necessary. At one journal, only external experts decide on whether to publish articles $(3 \%)$. The decision on whether to accept an article is in most cases taken by one editor alone, with the possibility of consulting other editors. In some cases, a unanimous $(16 \%)$ or a majority $(8 \%)$ agreement of the entire editorial board is necessary. In this case, the number of assessments per article varies. No conclusions can be drawn about the anonymity of authors and assessors as a result of the low numbers of responses.

In addition, it came to light that the sporadically or regularly contacted external experts comprise university professors $(40 \%)$, other university researchers $(20 \%)$, and legal practitioners $(30 \%)$. The internal editorial boards are made up of legal practitioners $(52 \%)$, university professors $(38 \%)$, other university staff $(5 \%)$, and others $(5 \%)$. In $70 \%$ of cases, the authors need not meet any specific requirements to be able to submit an article (in $20 \%$ of cases, for example, they must have a university degree, be a member of an institute, have a relevant job, etc.). Further, $8 \%$ of the journals say that the authors should either be specialists in the field in question or at least hold an academic qualification.

Bibliometric methods are not used to assess the quality of publications in the evaluation situations considered here.

\subsubsection{Assessment of the evaluation procedures}

Law professors were questioned in the survey about their opinions on the difficulties of evaluating research. ${ }^{18}$ The survey allows conclusions to be reached in relation to the procedures used for research evaluation (cf. Fig. 2). The professors regard the most serious difficulty to be assessment procedures that are too unilaterally quantitative $(77 \%$ agreed). It is interesting that current assessment procedures are basically regarded as too unilaterally quantitative, even though quantitative procedures for assessment of publications are hardly ever used. Great importance was attached to the statements that there are no appropriate assessment criteria for evaluating research $(73 \%)$, existing evaluation procedures are biased towards external expectations of the research rather than the goals of the research community ( $72 \%)$, assessments take too long ( $72 \%)$, and evaluations lead to undesirable incentives in relation to 


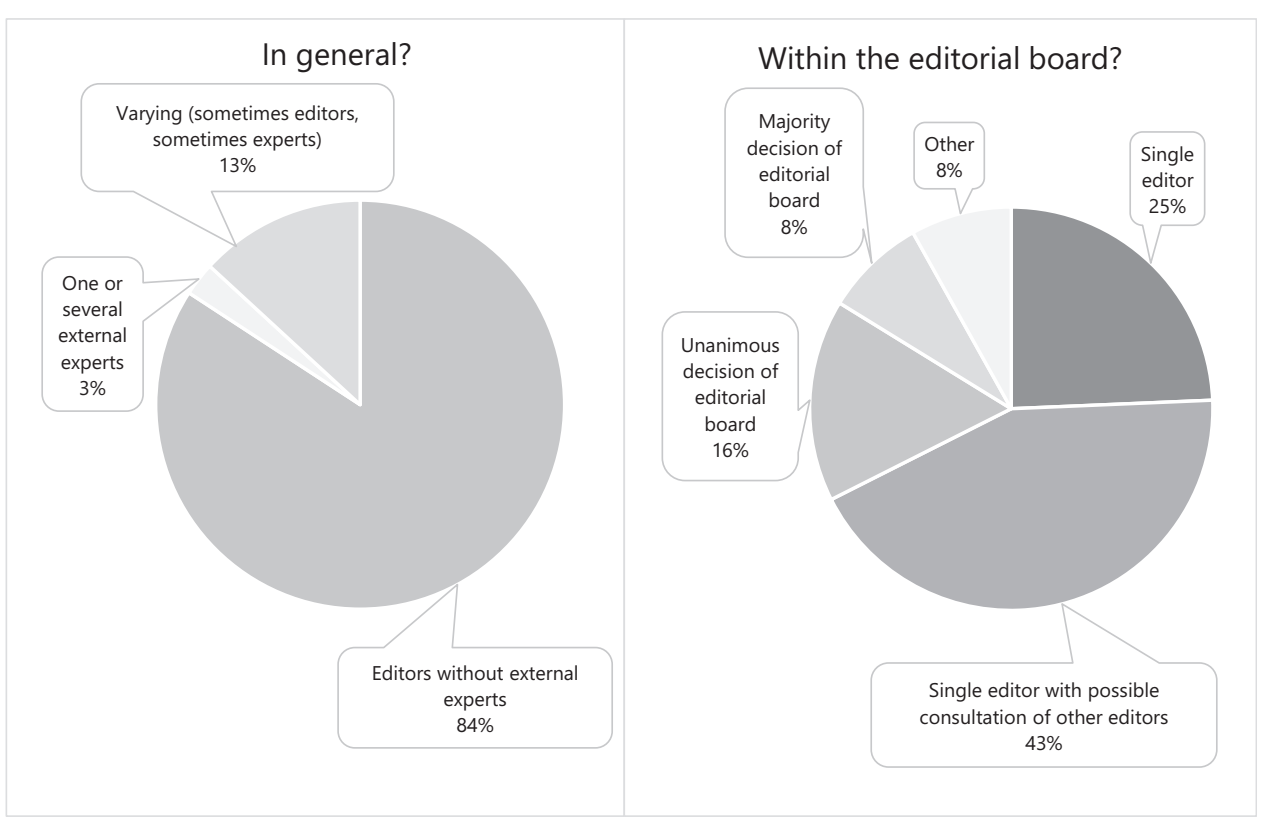

Figure 1. Composition of decision committees at law journals [shown as a percentage].

publication behaviour $(71 \%)$. The statement that assessment procedures are too unilaterally qualitative, on the other hand, does not receive much support (only 24\%). There was also little agreement with the statement that there are not sufficient numbers of qualified experts who can carry out an assessment $(39 \%)$.

\subsubsection{Conclusions}

With regard to journals, in most cases, the decision on accepting an article for publication is taken by the editorial board, which is normally made up of professors and legal practitioners, without consulting external experts. As non-academics (such as practising lawyers or judges) are often also members of editorial boards, the term "peer" must be understood in a broader sense. It may be assumed that a selection process for the submitted works takes place, but that this does not follow the traditional double-blind peer review procedure.

Interestingly, however, the professors questioned on the quality of law journals underlined the importance of the double-blind peer review procedure. We are unable to conclude with any certainty whether the absence of systematic double-blind peer reviews is a result of the comparatively high amount of work and cost of such a procedure, the segmented research environment, linguistic barriers, or the comparatively small number of suitable reviewers.

Bibliometric procedures that use citation analyses or impact factors meet with especially strenuous resistance. This is hardly surprising, as the peculiarities of academic legal research place clear limits on the suitability of bibliometrics. Nevertheless, citation has a long tradition in legal science (Hug and Ochsner 2015: 351f; Shapiro 1992: 377ff). Legal texts by other authors and court judgements, for example, have always been cited in academic legal publications. Citation analyses have been used for a long time, in particular in relation to citations in court judgements (Perry 2006: 23; Devinat 2015: 335ff). However, citation analyses do not provide sufficient information for the evaluation of academic legal research projects, because they do not provide data sources that could be used as a basis for conducting analyses (see in summary Lienhard, Amschwand and Herrmann 2013: 411ff; Tanquerel and Flückiger 2015: 9, 17f, 239ff and 409ff). In any case, the diversity of languages, subject-specific segmentation, and the low numbers of publications recorded in research databases make it hard to use relevant data sources. Problems are also caused by the categorization of publications and the specific choice of the publication type (for example, monographs, anthologies, or commentaries) whose citation data are not listed in databases. The attempt to evaluate academic legal research using bibliometric procedures (in particular, citation analyses) would thus lead to misleading results. This also corresponds to the results of Ochsner et al. who demonstrated that many criteria used for evaluating research projects are not accepted by the research communities because they are of a highly quantitatively operationalizable character (Ochsner, Hug and Daniel 2012: 4ff.; see Hug and Ochsner 2015: 351ff, applied to legal science). Their study reached the conclusion that very few criteria accepted by the research community can be described using quantitative measurement values.

Various research projects in the European environment have also tried to find worthwhile evaluation procedures for academic legal research (VLIR 2005: 3ff; Luwel et al. 1999: 498ff; Moed, Luwel and Nederhof 2002: 498ff; De Jong et al. 2011: 61ff; AERES 2014: $1 \mathrm{ff})$. However, no procedure that is "the most suitable" for evaluating academic legal research emerges from a comparison of the reports on the various evaluation procedures. Citation analysis is not used in any of the evaluation procedures. Often there is too little bibliographical data available for a bibliometric analysis of research to be made, as comparatively little academic legal research is published in journals and the data from the remaining publications are not provided in legal or large international databases. Nor is the pure peer review much used owing to the time required for the procedure. The studies examined indicate that a combination of evaluation procedures is the preferred method (Luwel et al. 1999: 124; 


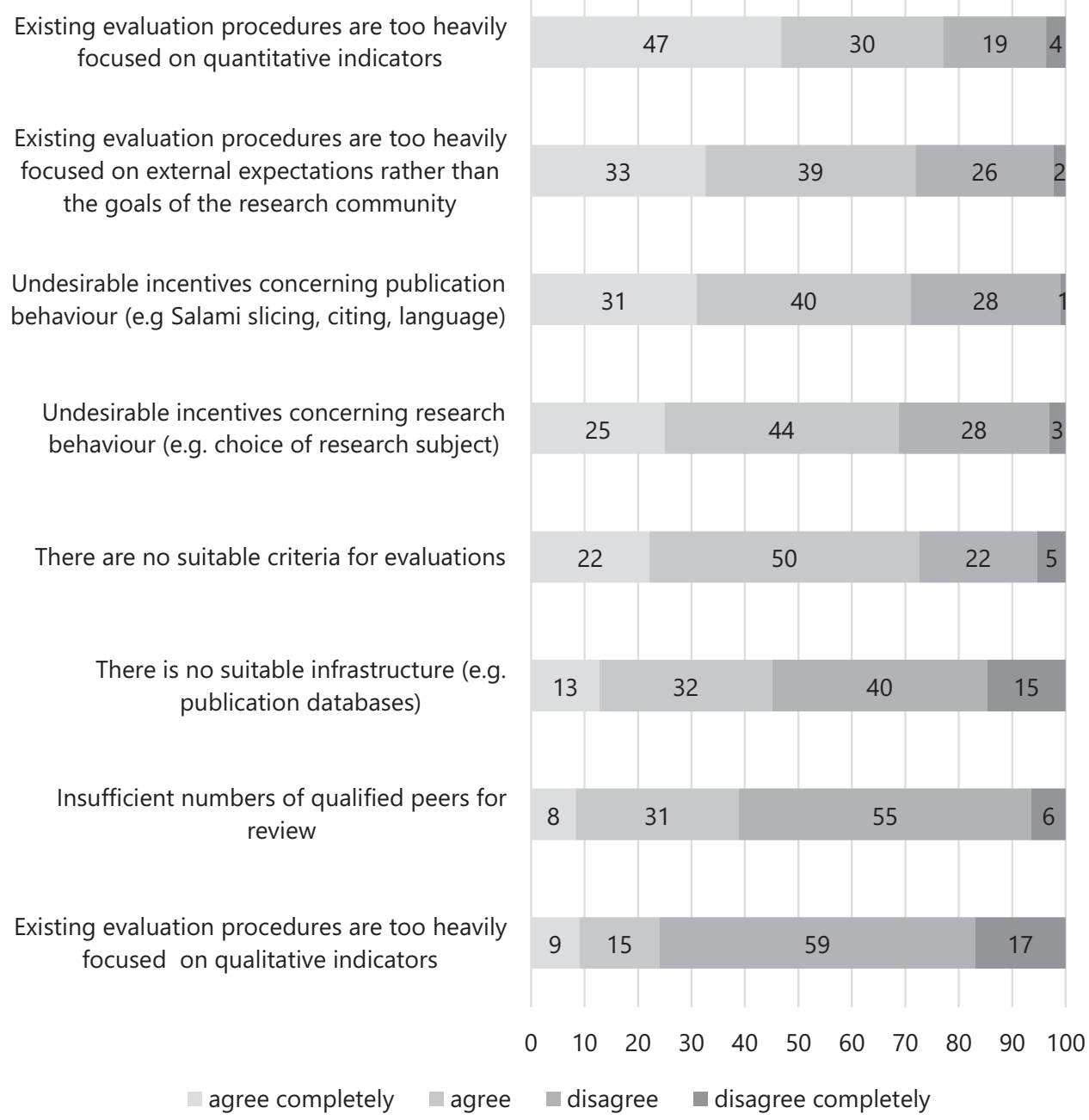

Figure 2. Law professors—difficulties in evaluating legal research [shown as a percentage].

Moed, Luwel and Nederhof 2002: 498ff; De Jong et al. 2011: 61ff; AERES 2014: 1ff). According to some authors, a combination of peer reviews with quantitative procedures, taking account of national contexts, can compensate for the defects in exclusively quantitative or exclusively qualitative procedures (Hornbostel 2010: 304). Luwel et al. used this combination, for example, to elicit "indicators of scholarly performance" (Luwel et al. 1999: 131ff). Moed, Luwel, and Nederhof used a combination of procedures to develop a classification system for academic legal publications by asking the research community about its concept of quality (Moed, Luwel and Nederhof 2002: 505f). The answers have been compared with bibliographic data on individual publications. The reports do not indicate whether the procedures, in particular the combination of methods, have proven their value. Nonetheless, these studies focused primarily on the evaluation of research institutions.

\subsection{Evaluation criteria}

\subsubsection{Existing evaluation criteria}

Only two of the 30 editorial boards of law journals (7\%) that were questioned said that contributions were selected on the basis of criteria set out in a written document (formalized) $(7 \%) .{ }^{19}$ However, the editorial rules of these two journals do not lay down any qualitative criteria. Instead they specify formal requirements such as the method of citation, structure, language, originality, etc. It must therefore be assumed that the evaluation process is primarily based on implicit criteria.

In general, it is difficult to establish what criteria are used for assessing academic legal publications. Hardly any (written) criteria have been adopted by Swiss universities in their legal principles, for example. Although scientific publications are certainly taken into account when evaluating university institutes or persons applying for scientific posts or promoted posts (see Lienhard et al. 2016: 153, 158 ), the criteria for their assessment, apart from noting the number of publications, are rarely mentioned. In general, publications are only differentiated on the basis of their type (monograph, journal articles). The use of citation indices or quality indicators from journals is only mentioned in a small number of cases, whereby the peculiarities of the specialist field must be taken into account. Indeed, universities have hardly adopted any written criteria for assessing dissertations; all that is required is that they are independent scientific contributions (Lienhard et al. 2016: 139f).

All universities have principles governing what to do in the case of academic misconduct though (Lienhard et al. 2016: 111). 


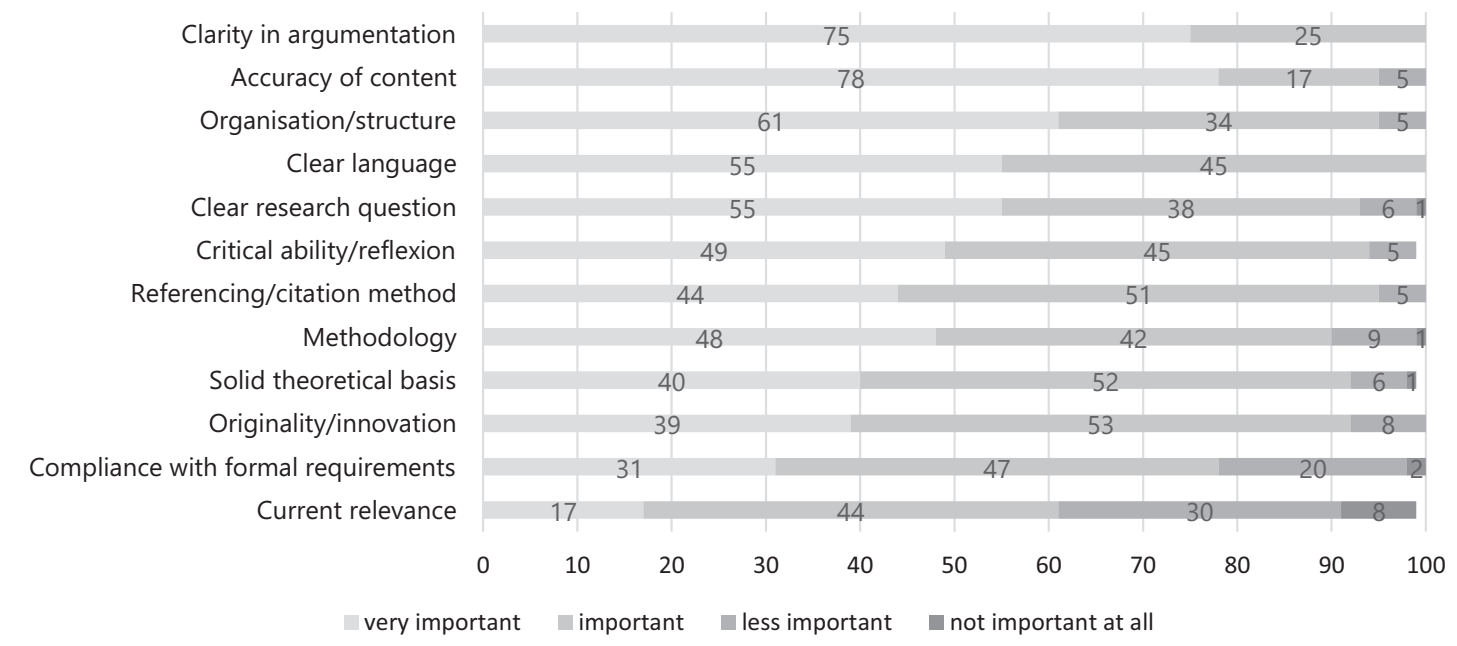

Figure 3. Law professors—criteria for assessing academic legal publications ${ }^{28}$ [shown as a percentage].

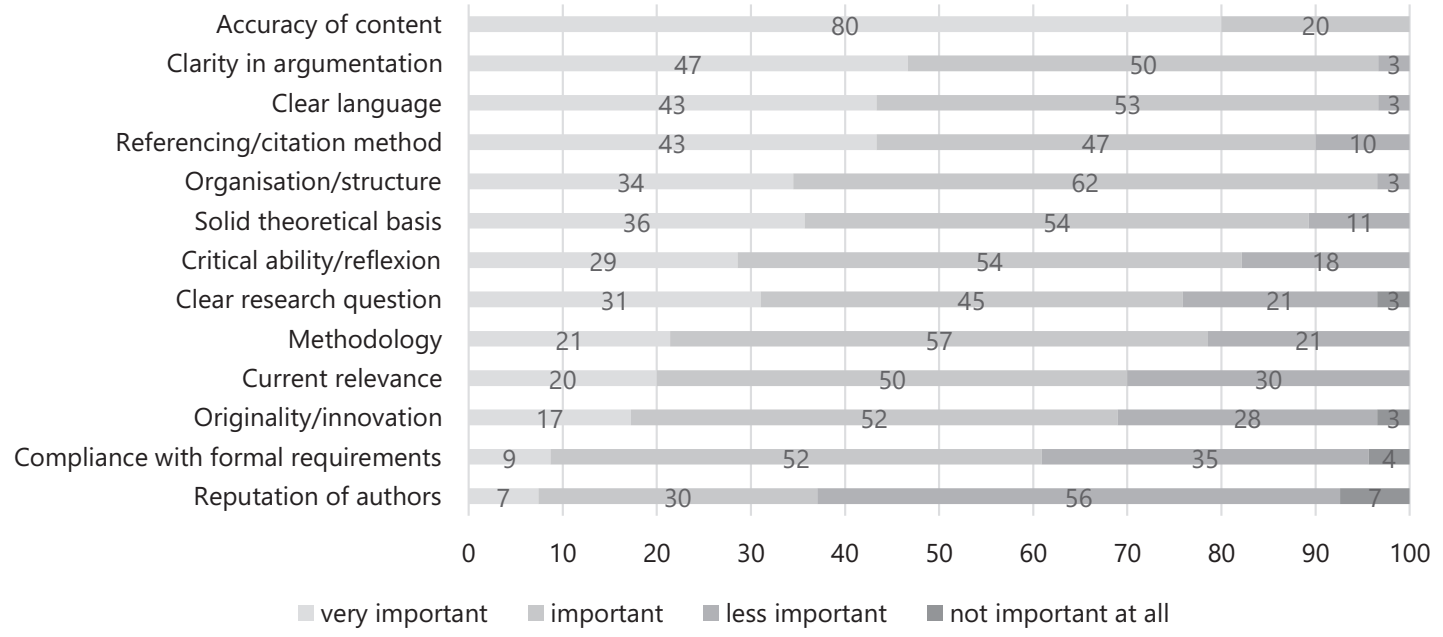

Figure 4. Editors—criteria for assessing academic legal publications [shown as a percentage].

Misconduct takes place if research data are manipulated, other people's work is not correctly referenced in a research work, or if the incorrect procedure is followed for drawing up reports. In our view, however, these rules do not constitute quality criteria, but minimum standards that must be met before a work are assessed. If these standards are not met, the work simply cannot be regarded as scientific.

\subsubsection{Assessment of the evaluation criteria}

Professors, legal practitioners, and editors of law journals were asked what relevance ${ }^{20}$ they attach to certain criteria ${ }^{21}$ for assessing academic legal publications.

The professors basically regard all the criteria as useful, and two criteria (clarity in argumentation and clear language) are even regarded by all those questioned as at least important (cf. Fig. 3). ${ }^{22}$ Clarity in argumentation and accuracy of content are regarded as the most important criteria overall. Also important are the organisation/structure and clear language in a publication. The least important criteria are considered to be current relevance and compliance with formal requirements. ${ }^{23}$

The editors essentially regard the same criteria as important as the professors do. Accordingly, the criteria accuracy of content, clarity in argumentation, and clear language are considered essential (cf. Fig. 4). Current relevance, originality/innovation, and compliance with formal requirements are again regarded as less important. What is noticeable is that the reputation of authors is seen as comparatively unimportant.

The picture is similar when it comes to legal practitioners. Here four criteria (accuracy of content, organisation/structure, clarity in argumentation, and clear language) are regarded by all those questioned at least as being important (cf. Fig. 5). Legal practitioners see the criteria of critical ability/reflexion, methodology, and originality/innovation as being less important than the professors do. On the other hand, current relevance is regarded as important. Also less important is compliance with the formal requirements. 


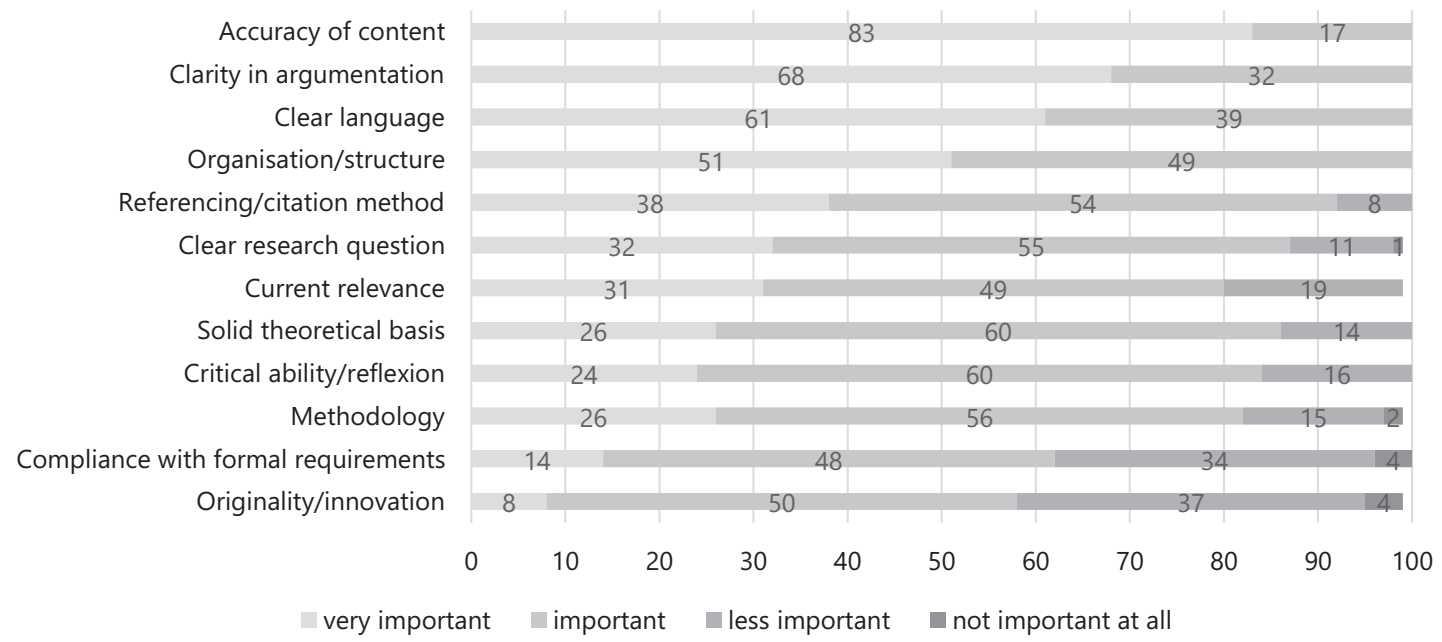

Figure 5. Practising lawyers—criteria for assessing academic legal publications [shown as a percentage].

When comparing the three groups (professors, practising lawyers, and editors), the first noticeable difference concerns the overall perception of importance of the criteria. With few exceptions, professors consider all the criteria as being important. However a noticeable difference to the other groups exists particularly for the criteria of clear research question, compliance with formal requirements, critical ability/reflexion, and methodology, as well as originality/innovation. Results show that a sound methodological approach and a clear research question are of bigger importance in an academic setting than in legal practice. A $Z$ score test, as a measure of the standard deviation, and the associated P-value show that the differences between the professors and the practising lawyers regarding these two criteria are statistically significant ${ }^{24}$, whereas this is not the case for the editors ${ }^{25}$. Yet to conclude, on the basis of the collected data, on a general mismatch between academia and legal practice would be going too far. However, the differences concerning these criteria are not that surprising. The relative importance of the ability to think critically and to do original research might also have something to do with the particularities of academia and the self-conception of professors. If the mission of a (legal) scientist is to advance scientific knowledge, critical thinking and innovative research play a central role. On the other hand, lawyers consider, compared with both other groups, one criterion as more important, namely, the current relevance. As academic legal publications are widely read with respect to law practice, this result is not surprising. The question of what these criteria actually mean and if professors, practising lawyers, and editors interpret them in the same way cannot be answered here. This should be tested in future research. Interesting is that all three groups seem to be more focused on the quality of interpretation and argumentation in legal publications than, for example, on methodological rigour, even though one would suspect a link between both types of criteria. It should be rather difficult to determine the quality of argumentation if the author of a legal publication does not make his/her methodological choices explicit.

Overall, in our view the most striking finding is a lack of differences between the three groups. Most of the criteria are equally being viewed as important or not important. One possible explanation for this outcome could (again) lie in the strong interconnection between academic legal science and law practice. As seen in Section 4.2.1, editorial boards are to a substantial degree made up of law professors and academics often also work in law practice (Section 2.1.9).

\subsubsection{Conclusions}

The investigations have shown that scientific law journal contributions are hardly ever selected on the basis of written (formalized) criteria. If criteria exist, they are not an indicator of quality of content, but instead specify formal requirements such as language of publication, form of citation, or structure. However, it is obvious that implicit value judgements of what makes good research are part of the evaluation process.

The surveys of professors, practising lawyers, and editors reveal that there is a consensus in relation to the criteria regarded as most important. Clarity in argumentation, clear language, and accuracy of content in publications are considered by all participants to be very important. In general, however, it can be said that all the criteria suggested are regarded by the research community as important, and, to this extent, there is a certain level of agreement. Only compliance with formal requirements and originality/innovation were seen by all the groups as comparatively less important.

However, two caveats remain: on the one hand, as the essence of these criteria is not clear, different assessors might not have the same concept of a specific criterion. On the other hand, it is not obvious if and how these criteria can be measured. While the respondents seem to consider the quality of research as a key criterion, there is no general agreement on how to define quality. Finding a way to do that requires an in-depth debate among the research community and further research.

\section{Appraisal and outlook}

\subsection{Key findings}

The following preliminary results seem to be of crucial importance with regard to the procedures: although peer reviews take place, double-blind reviews are extremely rare. Editors often decide without consulting external experts and regularly make their own decision on whether to accept an article for publication. At the same time, professors regard the double-blind peer review procedure as an important sign of the quality of a law journal. Quantitative approaches are not used to assess publications. ${ }^{26}$ In particular, the research community has a highly sceptical 
attitude towards bibliometrics. The theoretical analyses also show that indicators used for evaluating research projects in other disciplines (such as international relevance, impact factors, frequency of citation, rated journals, external funding) cannot be applied indiscriminately to academic legal research (for a detailed overview, see Lienhard et al. 2016: 29ff). Impact factors, such as those calculated with the aid of the $\mathrm{H}$-index or frequency of citation, cannot be regarded as suitable aids. The informative validity of such quantitative indices only becomes apparent by contextualizing in the relevant specialist field. They must be adapted for each object being evaluated and to its general context.

Formalized quality criteria for the assessment of scientific publications are rarely encountered, with the exception of formal selection requirements rather than quality assessment criteria. As far as assessing the suitability of quality criteria is concerned, the empirical investigations have shown that there is some common ground. For example, professors, editors, and legal practitioners consider criteria such as accuracy of content and clarity in argumentation as very important when assessing the quality of an academic legal publication. Members of the research community and legal practitioners take differing views on the significance of criteria such as current relevance and originality/innovation. Still, on the whole, there does not seem to be a fundamental division between the opinions of professors and of legal professionals. In the course of the investigations, it became apparent that it is neither clear what the substance of quality criteria is nor who can provide a proper definition. Thus there is a lack of assessment factors that can make these criteria more specific. Quality assessments are instead based on the subjective, unexpressed expectations of quality held by the assessors (tacit knowledge skills). Accordingly, no conclusive remarks can be made about various concepts of quality and no reliable characteristics or indicators of the individual quality criteria can be identified.

The results so far confirm that the legal research community has an interest in establishing its own quality procedures and quality criteria. The bottom-up approach has proven its value; despite all their doubts about whether the quality of legal research can be measured, researchers recognize that a discussion about quality criteria and procedures can also encourage self-reflexion within the research community with regard to research methods and research objectives. At the same time, it cannot be excluded that pressure on researchers to evaluate their research will continue to rise. Thus it is inevitable that researchers, as experts in the area, need to discuss this beforehand.

\subsection{Need for further research}

A significant proportion of academic legal research results are addressed to legal practitioners and other users of research results outside the academic community. Thus the quality of academic legal research is very important. At the same time, the research also serves to generate new scientific findings and thus to develop scientific knowledge within the research community. However, there does not seem to be any actual consensus on quality standards in the various evaluation situations, whether in Switzerland or elsewhere. In view of these circumstances, international comparative research projects become especially important (Tanquerel and Flückiger 2015). In particular they should identify the evaluation situations in other countries and devise best practices. In the course of such research, evaluation procedures and criteria should be investigated in more detail from an international comparative perspective. Existing procedures for assessing legal research projects should be identified and the quality criteria and indicators that are used should be analysed on a comparative basis. In addition alternatives to existing evaluation procedures should be pointed out. Similar issues are being investigated as part of an ongoing European research project. ${ }^{27}$

\section{Notes}

1. The key results in this paper come from a research project (project managers: A. Lienhard [University of Bern], A. Flückiger, T. Tanquerel [both University of Geneva]) initiated by swissuniversities on "Research evaluation in legal science": Lienhard et al. (2016).

2. See in general the summary in Amschwand (2014: 213ff) with numerous references.

3. For an overview of experiences in developing evaluation procedures for legal science in other European countries, see Lienhard, Amschwand and Herrmann 2013: 411f; and Lienhard et al. 2015: 391f.

4. Belgium (Flanders): VLIR, Final report 1996; Luwel et al. 1999; VLIR, Model 2005. Germany: Wissenschaftliche Kommission Niedersachsen 2002; Grapatin et al. 2012. Netherlands: VSNU Judicial research 1996; VSNU Prestatie-indicatooren 2007; De Jong et al. 2011; Van Boom and Van Gestel 2015.

5. For an overview of experiences in developing evaluation procedures for legal science in other European countries see Lienhard, Amschwand and Herrmann 2013: 426f; Tanquerel and Flückiger 2015: $409 \mathrm{ff}$.

6. For example, Lienhard et al. (2016: 12ff) identify seven situations in which (academic legal) research is assessed.

7. Where criteria are mentioned below, unless otherwise indicated, these also include the corresponding indicators.

8. Since 1 January 2015, renamed the Swiss University Conference (SUC).

9. For some recent contributions to this question, see Engel and Schön 2008; Senn and Fritschi 2009.

10. For a detailed discussion on the difference between quality and practical value in research, see Lienhard et al. 2016: 47ff.

11. See the approach adopted by Hug, Ochsner and Daniel 2013: 369ff; Hug, Ochsner and Daniel 2010: 111ff.

12. See also De Jong et al. 2011: 9ff; VLIR 1996; Luwel et al. 1999; Gutwirth 2009: 74; Lienhard, Amschwand and Herrmann 2013: 4; Schwander 2002: 106f; Van Gestel and Vranken 2011: 922; Hug and Ochsner 2015: 362; Amtenbrink and Castermans 2015: 466; Zuppiroli 2015: 25; Van Gestel 2015: 52.

13. Lienhard, Amschwand and Herrmann 2013: 4; Schwander 2002: 106f; Van Gestel and Vranken 2011: 922.

14. As for example: 'How important are the following criteria in order to assess an academic legal publication?' Respondents could rate their answers on a Likert Scale from criteria 'very important', 'important', 'less important' to 'not important at all.

15. The response rate corresponds approximately to the distribution among the statistical population with regard to the university affiliation, linguistic region, mother tongue, and specialist field. See also Lienhard et al. 2016: $15 \mathrm{f}$

16. For each canton, a randomly generated survey was carried out in German, French, and Italian. The number of practicing lawyers interviewed per canton was ascertained from the ratio to their overall number in Switzerland. All lawyers whose email address is available in the SAV address database were taken into account. The percentage of lawyers participating in the survey is representative in relation to the statistical population of lawyers contacted. 
17. Using the online survey application Limesurvey, see https:// www.limesurvey.org/

18. The answers do not relate only to the evaluation of publications, but to research evaluations in general.

19. 13 journals did not answer this question.

20. The answers specified were: very important, important, less important, and not important at all.

21. Referencing/citation method, organization/structure, clear research question, methodology, compliance with formal requirements, clear language, accuracy of content, clarity in argumentation, current relevance, originality/innovation, critical ability/reflexion, solid theoretical basis, and reputation of authors (only for editors).

22. The sample was tested for language, university affiliation, age, sex, field of research, and type of research. No significant differences were found between the categories (for more information, see Lienhard et al. 2016: 15f).

23. As part of the survey, an investigation was also conducted into which criteria are regarded as important when assessing dissertations. It is interesting that the criteria theoretical support, critical ability/reflexion, and methodology are regarded as more important when assessing dissertations than when assessing work that is intended for publication. Current relevance on the other hand is regarded as more important for publications than it is for dissertations.

24. Criteria sound methodological approach: $Z$ test for two proportions (professors and practicing lawyers), twofold, $\alpha=$ $0.05, \mathrm{P}=0.0201, \mathrm{n} 1=52, \mathrm{n} 2=53$. Criteria clear research question: $\alpha=0.05, \mathrm{P}=0.0098, \mathrm{n} 1=60, \mathrm{n} 2=65$. Furthermore, a chi-square test was used as recommended by Campbell (2007) and Richardson (2011), and the confidence interval is calculated according to the recommended method given by Altman et al. (2000).

25. Criteria sound methodological approach: $\mathrm{Z}$ test for two proportions (editors and professors), twofold, $\alpha=0.05, \mathrm{P}=0.2123, \mathrm{n} 1$ $=6, \mathrm{n} 2=52 . \mathrm{Z}$ test for two proportions (editors and practicing lawyers), twofold, $\alpha=0.05, \mathrm{P}=0.7917, \mathrm{n} 1=6, \mathrm{n} 2=53$. Criteria clear research question: $\mathrm{Z}$ test for two proportions (editors and professors), twofold, $\alpha=0.05, \mathrm{P}=0.2011, \mathrm{n} 1=9, \mathrm{n} 2$ $=60 . \mathrm{Z}$ test for two proportions (editors and practicing lawyers), twofold, $\alpha=0.05, \mathrm{P}=1.0000, \mathrm{n} 1=9, \mathrm{n} 2=65$.

26. When evaluating the research projects of an institute or of persons, simple bibliometric procedures such as counting publications are used.

27. Van Gestel R. and Lienhard A. (Eds.) (forthcoming).

28. The order of criteria is based on weighting the answers in the four different categories (very important to not important) with a number from 4 to 1 , from which the average was calculated.

\section{Funding}

This work was supported by swissuniversities, the Rectors Conference of the Swiss Universities, within the research programme 'Research performances in humanities and social sciences'.

\section{References}

AERES - L'Agence d'évaluation de la recherche et de l'enseignement supérieur (2014) Critères d'évaluation des entités de recherche, Le référentiel de l'AERES, Version du 3 novembre 2014.
Altman, D. G., Machin, D., Bryant, T. M., Gardner, M. T. (eds) (2000) Statistics with Confidence: Confidence Intervals and Statistical Guidelines, 2nd edn, BMJ Books.

Amschwand, F. (2014) Qualitätssicherung Im Schweizerischen Hochschulwesen, Verfassungsrechtlicher Rahmen Und Leitlinien Für Die Umsetzung an Den Hochschulen. Bern: Stämpfli.

Amtenbrink, F., and Castermans, A. G. (2015) 'Evaluating Dutch Legal Research Quality Assessment', in Tanquerel, T. and Flückiger, A. (eds) L'évaluation De La Recherche En Droit: Enjeux Et Méthodes, p. $447 \mathrm{ff}$. Brussels: Bruylant.

Arzt, G. (1996) Einführung in Die Rechtswissenschaft, 2nd edn. Basel: Helbing \& Lichtenhahn.

Aseeva, A. (2015) 'La Production à La Chaîne Du Savoir Juridique', in Tanquerel, T. and Flückiger, A. (eds) L'évaluation De La Recherche En Droit: Enjeux Et Méthodes, p. 277ff. Brussels: Bruylant.

Bégasse de Dhaem, P., and Van Waeyenberge, A. (2015) 'Gouverner Par Les Indicateurs: Le Cas Des Classements D'université', in Tanquerel, T. and Flückiger, A. (eds) L'évaluation De La Recherche En Droit: Enjeux Et Méthodes, p. 255ff. Brussels: Bruylant.

Campbell, I. (2007) 'Chi-Squared and Fisher-Irwin Tests of Two-by-Two Tables with Small Sample Recommendations', Statistics in Medicine, 26/19: 3661-75.

CEST - Center for Science and Technology Studies (2007) Darstellung, Vergleich Und Bewertung Von Forschungsleistungen in Den Geistes- Und Sozialwissenschaften, Bestandesaufnahme Der Literatur Und Von Beispielen Aus Dem in- Und Ausland, Bern: CEST.

Chérot, J.-Y. (2015) 'Usages De L'évaluation De La Recherche Et Pilotage Du Secteur Public Académique, Enjeux Pour La Recherche En Droit', in Tanquerel, T. and Flückiger, A. (eds) L'évaluation De La Recherche En Droit: Enjeux Et Méthodes, p. 239ff. Brussels: Bruylant.

Costa, D. (2015), 'AERES/ANVUR: Une Comparaison Franco-Italienne Des Processus D'évaluation De La Recherche Juridique', in Tanquerel, T. and Flückiger, A. (eds) L'évaluation De La Recherche En Droit: Enjeux Et Méthodes, p. $409 \mathrm{ff}$. Brussels: Bruylant.

CRUS - Rektorenkonferenz der Schweizer Universitäten, Projet de Coopération et D'innovation (2008-2011/2012) Mesurer les performances de la recherche “(PCI B-05), (cit. CRUS, Project 2008-2011).

CRUS - Rektorenkonferenz der Schweizer Universitäten, SUK-Programm (2013-2016) P-3 "Performances de la recherche en sciences humaines et sociales”. (cit. CRUS, SUK-Programm 2013-2016)

De Jong, S. et al. (2011) 'Evaluation of Research in Context: An Approach and Two Cases', Research Evaluation, 1: 61ff.

Devinat, M. (2015) 'Les Citations Par Les Tribunaux Comme Mode D'évaluation Des Travaux Universitaires En Droit: étude Critique Fondée Sur Les Références Jurisprudentielles à L'ouvrage Interprétation Des Lois', in Tanquerel, T. and Flückiger, A. (eds) L'évaluation De La Recherche En Droit: Enjeux Et Méthodes, p. $335 \mathrm{ff}$. Brussels: Bruylant.

Donovan, C. (2008), 'Das Zweiköpfige Lama Zähmen: Die Australische Suche Nach Den Besten Evaluierungsmethoden Für Die GW', in Lack, E. and Markschies, C. (eds) What the Hell Is Quality? Qualitätsstandards in Den Geisteswissenschaften, p. 77ff. Frankfurt/New York: Campus Verlag.

Edwards, H. T. (1992) 'The Growing Disjunction between Legal Education and the Legal Profession', Michigan Law Review, 91: 34-78.

Engel, C. and Schön, W. (eds) (2008) Das Proprium Der Rechtswissenschaft. Tübingen: Mohr Siebeck.

Gingras, Y. (2014) Les Dérives De L'évaluation De La Recherche, Du Bon Usage De La Bibliométrie. Paris: Raisons d'agir.

Glenn, H. P. (2014) Legal Traditions of the World: Sustainable Diversity in Law, 5th edn. Oxford: Oxford University Press.

Grapatin, T. et al. (2012) Kriterien Zur Messung Der Forschungsleistung an Der Heinrich-Heine-Universität Düsseldorf, Abschlussbericht Der AG Leistungsparameter. Düsseldorf: Heinrich-Heine-Universität Düsseldorf.

Gutwirth, S. (2009) 'The Evaluation of Legal Science, the Vl.IR.-Model for Integral Quality Assessment of Research Law: What Next', in Eisendrath, H. and Van Bendegem, J. -P. (eds) It Takes Two to Do Science. The Puzzling Interactions between Science and Society, p. 69ff. Brussels: Vubpress. 
Havemann, F. (2009) Einführung in Die Bibliometrie, Berlin: Gesellschaft für Wissenschaftsforschung.

Herbert, U., and Kaube, J. (2008) 'Die Mühen der Ebene: Über Standards, Leistung und Hochschulreform', in Lack, E. and Markschies, C. (eds) What the Hell Is Quality? Qualitätsstandards in Den Geisteswissenschaften, p. $37 f f$. Frankfurt/New York, NY: Campus Verlag.

Hornbostel, S. (2008) 'Gesucht: Aussagekräftige Indikatoren und Belastbare Datenkollektionen, Desiderate Geisteswissenschaftlicher Evaluierung in Deutschland', in Lack, E. and Markschies, C. (eds) What the Hell Is Quality? Qualitätsstandards in Den Geisteswissenschaften, p. 55ff. Frankfurt/New York, NY: Campus Verlag.

Hornbostel, S. (2010) '(Forschungs-)Evaluation', in Simon, D., Knie, A., Hornbostel, S. (eds) Handbuch Wissenschaftspolitik, p. 293f. Wiesbaden: Verlag für Sozialwissenschaften.

Hug, S., and Ochsner, M. (2015) 'How Legal Scholars Could Change the Landscape of Research Evaluation', in Tanquerel, T. and Flückiger, A. (eds) L'évaluation De La Recherche En Droit: Enjeux Et Méthodes, p. 351ff. Brussels: Bruylant.

Hug, S., Ochsner, M., and Daniel, H.-D. (2014) 'A Framework to Explore and Develop Criteria for Research Quality in the Humanities', International Journal for Education, Law and Policy, 2014: 55ff.

Hug, S., Ochsner, M., and Daniel, H.-D. (2013) 'Criteria for Assessing Research Quality in the Humanities: A Delphi Study among Scholars of English Literature, German Literature and Art History', Research Evaluation, 5: 369ff.

Hug, S., Ochsner, M., and Daniel, H.-D. (2010) 'Entwicklung Von Qualitätskriterien Für Die Forschung in den Geisteswissenschaften - Eine Explorationsstudie in Den Literaturwissenschaften und der Kunstgeschichte', QiW, 4: 91ff.

Kischel, U. (2015) Rechtsvergleichung. München: C.H. Beck.

Kozar, G. (1999) Hochschul-Evaluierung: Aspekte der Qualitätssicherung Im Tertiären Bildungsbereich. Wien: facultas wuv Universitätsverlag.

Kronick, D. (1990) 'Peer Review in 18th Century Scientific Journalism', American Medical Association, 10: $1321 \mathrm{f}$.

Kunz, P. V. (2006) 'Einführung Zur Rechtsvergleichung in der Schweiz', Recht, 2: 37ff.

Lack, E., and Markschies, C. (2008) What the Hell Is Quality? Frankfurt/New York: Campus Verlag.

Larenz, K., and Canaris, C.-W. (1995) Methodenlehre der Rechtswissenschaft, 3rd edn. Berlin/Heidelberg/New York: Springer Verlag.

Lienhard, A., and Amschwand, F. (2010) 'Forschungsevaluation, Fachtagung Der Rechtswissenschaftlichen Fakultäten Der Schweiz Vom 25', Juni 2010, Bericht, November', Bern: Rechtswissenschaftliche Fakultät der Universität Bern.

Lienhard, A., Amschwand, F., and Herrmann, E. (2013) 'Forschungsevaluation in der Rechtswissenschaft: Ausgangslage, Entwicklungen und Ausblick', LeGes, 2: $411 \mathrm{ff}$.

Lienhard, A. et al. (2015) 'L'Évaluation De La Recherche En Droit En Suisse', in Tanquerel, T, and Flückiger, A. (eds) L'évaluation De La Recherche En Droit: Enjeux Et Méthodes, p. 373ff. Brussels: Bruylant.

Lienhard, A., Tanquerel, T., Flückiger, A., Amschwand, F., Byland, K., and Herrmann, E. et al. (2016) Forschungsevaluation in der Rechtswissenschaft: Grundlagen und empirische Analyse in der Schweiz. Bern: Stämpfli.

Luwel, M. et al. (1999) Towards Indicators of Research Performance in the Social Sciences and Humanities: An Exploratory Study in the Fields of Law and Linguistics at Flemish Universities, Brussels: Vlaamse Interuniversitaire Raad.

Maier, E. (2015) 'Assessment of Research in Austrian Faculties of Law Practice and Criticism for Some Selected Evaluation Processes', in Tanquerel, T, and Flückiger, A. (eds) L'évaluation De La Recherche En Droit: Enjeux Et Méthodes, p. 429ff. Brussels: Bruylant.

Moed, H., Luwel, M., and Nederhof, A. (2002) 'Towards Research Performance in the Humanities', Library Trends, 3: 498ff.
Ochsner, M., Hug, S., and Daniel, H.-D. (2012) 'Indicators for Research Quality in the Humanities: Opportunities and Limitations', Bibliometrie Praxis Und Forschung, 1: 4ff.

Perry, R. (2006) 'The Relative Value of American Law Reviews: A Critical Appraisal of Ranking Methods', Virginia Journal of Law and Technology, 1: 1ff. Pichonnaz, P. (2014) 'Bibliometrie en Droit: Quelques Réflexions Sur Les Enjeux et L'impact Sur La Littérature Juridique Future', ZSR 133: 377ff.

Posner, R. A. (1992) 'The Deprofessionalisation of Legal Teaching and Scholarship', Michigan Law Review, 91: 1921-8.

Reichert, S. (2013) 'Jenseits der Leistungsüberprüfung - Diskussionspapier Zur Suche Nach Einem Neuen Umgang Mit Qualitätssicherung an Hochschulen', SWTR-Schrift, 3: 22ff.

Richardson, J. T. E. (2011) 'The Analysis of 2 x Contingency Variables-Yet Again', Statistics in Medicine, 30/8: 890ff.

Schwander, V. (2002) Grundrecht der Wissenschaftsfreiheit im Spannungsfeld Rechtlicher und Gesellschaftlicher Entwicklungen. Bern: Paul Haupt.

Seckelmann, M. (2012) 'Autonomie, Heteronomie und Wissenschaftsadäquanz. Zur Wissenschaftsfreiheit Im Zeitalter Der „Evaluitis’, Wissenschaftsrecht, 45: 200-26.

Senn, M and Fritschi, B. (eds) (2009) Rechtswissenschaft und Hermeneutik. Stuttgart: Franz Steiner Verlag.

Shapiro, F. (1992) 'Origins of bibliometrics, citation indexing, and citation analysis: The neglected legal literature', Journal of the American Society for Information Science, 5: $337 \mathrm{ff}$.

Stolker, C. (2014) Rethinking the Law School. Cambridge: Cambridge University Press, $245 \mathrm{ff}$.

Tanquerel, T., and Flückiger, A. (eds) (2015) L'évaluation de la Recherche en Droit: Enjeux et Méthodes. Brussels: Bruylant.

Tschentscher, A. (2003) Grundprinzipien Des Rechts. Einführung in die Rechtswissenschaft mit Beispielen aus dem schweizerischen Recht. Bern: Paul Haupt.

Van Boom, W. H., and Van Gestel, R. (2015) 'Rechtwetenschappelijk Onderzoek - Uitkomsten Van Een Landelijke Enquête'(Legal Research Results of a National Survey', Nederlands Juristenblad, 2015/20: 1-38.

Van Gestel, R. (2015) 'Sense and Non-Sense of a European Ranking of Law Schools and Law Journals', Legal Studies, 35/1: 165-85.

Van Gestel, R. (2015) 'Evaluating Legal Research: About the Good, the Bad, and the Ugly', in Tanquerel, T, and Flückiger, A. (eds) L'évaluation de la Recherche en Droit: Enjeux et Méthodes, p. 27ff. Brussels: Bruylant.

Van Gestel, R., and Lienhard, A. (eds) (forthcoming) Evaluating Academic Legal Research in Europe. Cheltenham: Edward Elgar.

Van Gestel, R., and Vranken, J. (2011) 'Assessing Legal Research: Sense and Nonsense of Peer Review versus Bibliometrics and the Need for a European Approach', German Law Journal, 3/2011: 901ff.

VLIR-The Flemish Interuniversity Council (1996) 'The Assessment of Performance in Juridicial Research', Inter-University Committee of the Flemish Faculties of Law, Final Report, Brussels.

VLIR - The Flemish Interuniversity Council (2005) Model for the Integral Quality Assessment of Research in Law. Brussels: VSNU.

VSNU - Association of Universities in the Netherlands (1996) Review Committee on Juridicial Research, Quality Assessment of Research Rechtsgeleerdheit. Utrecht: VSNU.

VSNU - Association of Universities in the Netherlands (2007) 'Naar Prestatie-Indicatoren Voor Rechtswetenschappelijk Onderzoek', in Rapport Van De Commissie Prestatie-Indicatoren en Ranking, Ingesteld Door Het Disciplineoverlegorgaan Rechtsgeleerdheid van de VSNU. Utrecht: VSNU.

Wissenschaftliche Kommission Niedersachsen (2002) Forschungsevaluation an Niedersächsischen Hochschulen und Forschungseinrichtungen, Rechtswissenschaften, Ergebnisse und Empfehlungen. Hannover: Institut für Hochschulforschung.

Zuppiroli, L. (2015) 'Evaluation de la Recherche en Sciences et Technologie: Résultats et Bilan', in Tanquerel, T, and Flückiger, A. (eds) L'évaluation De La Recherche En Droit: Enjeux Et Méthodes, p. 17ff. Brussels: Bruylant. 